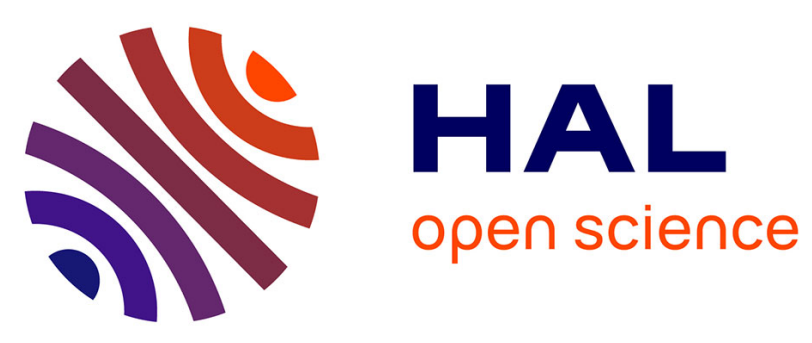

\title{
Crack Propagation Modeling in Silicon: A Comprehensive Thermomechanical Finite-Element Model Approach for Power Devices
}

Damien Calvez, Fabrice Roqueta, Sébastien Jacques, Laurent Bechou, Yves Ousten, Samuel Ducret

\section{To cite this version:}

Damien Calvez, Fabrice Roqueta, Sébastien Jacques, Laurent Bechou, Yves Ousten, et al.. Crack Propagation Modeling in Silicon: A Comprehensive Thermomechanical Finite-Element Model Approach for Power Devices. IEEE Transactions on Components Packaging and Manufacturing Technology Part B, 2014, 4 (2), pp.360-366. 10.1109/TCPMT.2013.2293094 . hal-01061431

\section{HAL Id: hal-01061431 https://hal.science/hal-01061431}

Submitted on 5 Sep 2014

HAL is a multi-disciplinary open access archive for the deposit and dissemination of scientific research documents, whether they are published or not. The documents may come from teaching and research institutions in France or abroad, or from public or private research centers.
L'archive ouverte pluridisciplinaire HAL, est destinée au dépôt et à la diffusion de documents scientifiques de niveau recherche, publiés ou non, émanant des établissements d'enseignement et de recherche français ou étrangers, des laboratoires publics ou privés. 


\title{
Crack Propagation Modeling in Silicon: A Comprehensive Thermomechanical Finite-Element Model Approach for Power Devices
}

\author{
Damien Calvez, Fabrice Roqueta, Sébastien Jacques, Laurent Bechou, \\ Yves Ousten, Member, IEEE, and Samuel Ducret
}

\begin{abstract}
Wafer handling during the manufacturing process introduces microcracks and flaws at the wafer edge. This paper aims at determining whether an initial crack would be able to propagate through the silicon active region of power devices when it is subjected to high electrothermal loads during operating conditions or accelerated thermal cycling tests. Failure analysis performed on these power devices has revealed some typical propagation paths. The most critical crack propagation cases (or paths) were determined by finite-element model simulations. The energy release rate has been calculated for different crack lengths, locations, or thermal loads, and then compared with the silicon critical energy release rate. Hence, different critical crack lengths have been determined. The effect of dice design, temperature, or mechanical properties of the materials on crack thresholds has been also investigated.
\end{abstract}

Index Terms-Brittle, crack propagation, energy release rate, fracture, power device, reliability, silicon.

\section{INTRODUCTION}

$\mathbf{N}$ UMEROUS papers have been published on the fracture mechanic of brittle materials, particularly focused on silicon [1]-[4]. These papers are usually written by experts who assume that the reader has an extensive knowledge in applied mechanics and particularly in fracture mechanics of materials. Engineers concerned with reliability assessments for microelectronic packaging applications may not have necessarily such an extensive background or sufficient time to study these complex fracture mechanic issues. In such a context, a finite-element model (FEM) can be developed to study crack growth in brittle materials and to evaluate reliability relative to these fracture issues. Crack propagation mechanisms are commonly investigated through dynamic models [5], analytical models [6], or both [7]. Brittle materials can be studied using linear elastic fracture mechanics (LEFM) and these

Manuscript received December 14, 2012; revised April 11, 2013; accepted October 29, 2013. Date of publication December 17, 2013; date of current version January 30, 2014. Recommended for publication by Associate Editor S. Liu upon evaluation of reviewers' comments.

D. Calvez, S. Jacques, L. Bechou, and Y. Ousten are with the IMS Laboratory, Talence F-33405, France (e-mail: damien.calvez@ ims-bordeaux.fr; sebastien.jacques@st.com; laurent.bechou@ims-bordeaux.fr; yves.ousten@ims-bordeaux.fr).

F. Roqueta and S. Ducret are with STMicroelectronics, 37071 Tours Cedex 2, France (e-mail: fabrice.roqueta@st.com; samuel.ducret@st.com).

Color versions of one or more of the figures in this paper are available online at http://ieeexplore.iee.org.

Digital Object Identifier 10.1109/TCPMT.2013.2293094 calculations are valid for silicon dice that are considered as brittles [8]. Thus, a rate-independent quasi-static fracture analysis can be performed to characterize the energy release rate associated with the corresponding crack growth.

In this paper, an LEFM-based FEM has been developed and applied on microelectronic devices to simplify implementation of complex fracture mechanics laws. This paper is focused on power components conducting several amps in various applications (home appliances or industrial applications). Regarding these applications, the silicon dice are commonly assembled in a TO-220AB package. One critical step, which could impact the die quality, is the sawing step, made on a wafer, before the die assembly.

Various surface roughnesses may be observed around the die (Fig. 1) depending on the quality of the sawing step and the dimensions of the silicon die and such a roughness could lead to cracks at the initial state presenting different lengths and depending on the process quality, sawing speed or blade dimensions. Such propagation phenomena could take place through the silicon due to high electrothermal stress levels from the loading conditions, i.e., during the operating conditions of the device. This paper aims to develop a model which is able to determine the critical crack length for each loading condition.

\section{2-D Linear Elastic Fracture Background}

Many laws are available to use fracture and damage mechanics. Most of these approaches require high knowledge and devote much time, which may not be compatible with industrial reliability purposes. LEFM can be used to simplify these studies and grants a suitable approach to evaluate crack propagation through brittle materials. LEFM can be applied on silicon, which is known as a brittle material [9]. Thus, its mechanical behavior can be described using a linear elastic law.

Two fracture criteria can be used to evaluate and predict crack propagation. Stress intensity factors $\left(K_{I}\right.$ and $\left.K_{I I}\right)$ are related to the stress state near the crack tip and linked to the different opening modes (tensile, in-plane shear and antiplane shear). The energy release rate $(G)$ corresponds to the energy dissipated during fracture per newly created fracture surface 


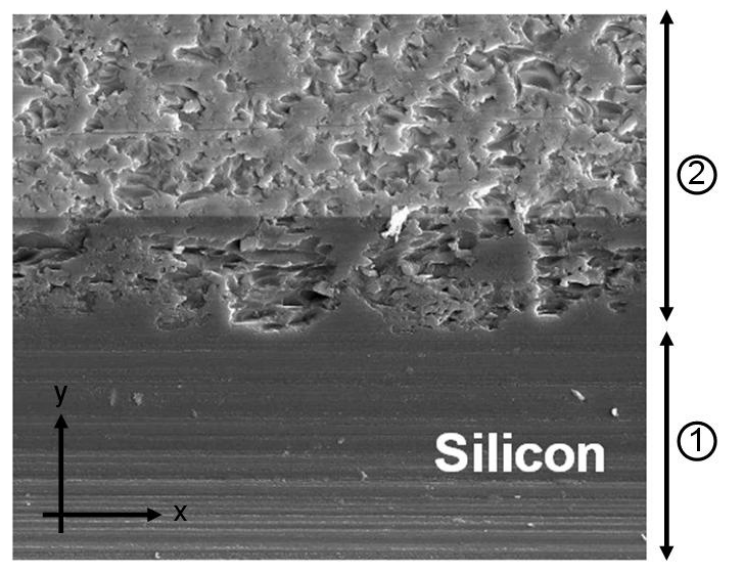

Fig. 1. Surface state of silicon sawing steps lead to different roughness (1 and 2).

area. Three methods are available for evaluation of these parameters:

1) $J$-integral calculation based on the integral domain approach [10];

2) direct energy-release rate calculation based on the virtual crack close technique [11];

3) stress-intensity factors calculated through displacement extrapolation [12].

For this paper, the $J$-integral method has been considered. Introduced in [10] and [13], the $J$-integral is directly linked to the energy release rate $G$ as described in

$$
J=G=-\left(\frac{\partial U}{\partial a}\right)
$$

where $\partial a$ is the length of the new cracked surface and $\Delta U$ the potential energy available for crack growth. Furthermore, some assumptions are required to use the $J$-integral method:

1) crack has been initiated;

2) plastic zone near crack tip is small;

3) points of analysis are near the crack tip $(r<0.1 \times$ crack length).

Silicon, which is known to be an anisotropic material, is also assumed to be isotropic. In this paper, the worst crystal plane regarding crack growth is studied, but the crack propagation may be impacted depending of the crystal plane of your material especially in case of crack bifurcation [14]. Moreover, anisotropic material properties of silicon were also simulated, but the effect on energy release rate was not significant.

$J$-integral calculations can be considered as valid for linear elastic, nonlinear elastic, and elastoplastic materials. As can be seen in (2) for linear elastic material, $J$-integral is related to the stress intensity factors

$$
J=\frac{1}{E}\left(K_{I}^{2}+K_{I I}^{2}\right)
$$

where $I$ and $I I$ denote two of the three fracture modes and $E$ is the Young's modulus. Energy release rate calculated from the $J$-integral method will be compared to the silicon critical energy release rate of the silicon $\left(G_{\mathrm{c}}\right)$ that is equal to the twice of the surface energy density $\gamma$ [15]

$$
G_{C}=2 \gamma \text {. }
$$

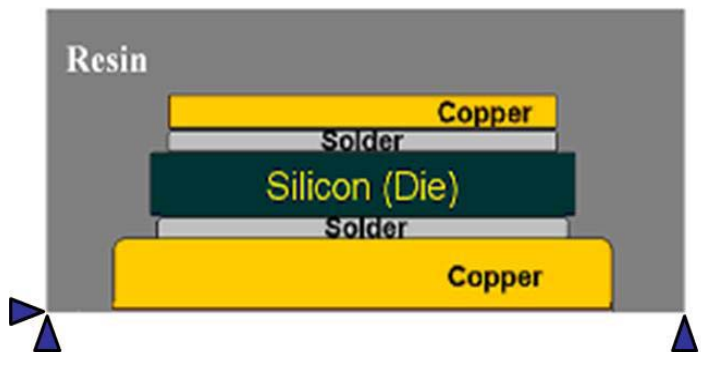

Fig. 2. Schematic cross section of a power device implanted for FEM simulations and degrees of freedom.

TABLE I

MechanicAl Properties of Materials [16]

\begin{tabular}{lccc}
\hline \hline \multicolumn{1}{c}{ Material } & E [GPa $]$ & $v$ & $\alpha\left[\mathrm{ppm} . \mathrm{K}^{-1}\right]$ \\
\hline Heat-sink (Cu) & 120 & 0.34 & 0.34 \\
Leadframe (KFC) & 120 & 0.34 & 0.34 \\
Die (Si) & 130 & 0.28 & 0.28 \\
Clip (Cu) & 120 & 0.34 & 0.34 \\
Resin (ECN) & 16.5 & 0.3 & 0.3 \\
Solder & 20.9 & 0.3 & 0.3
\end{tabular}

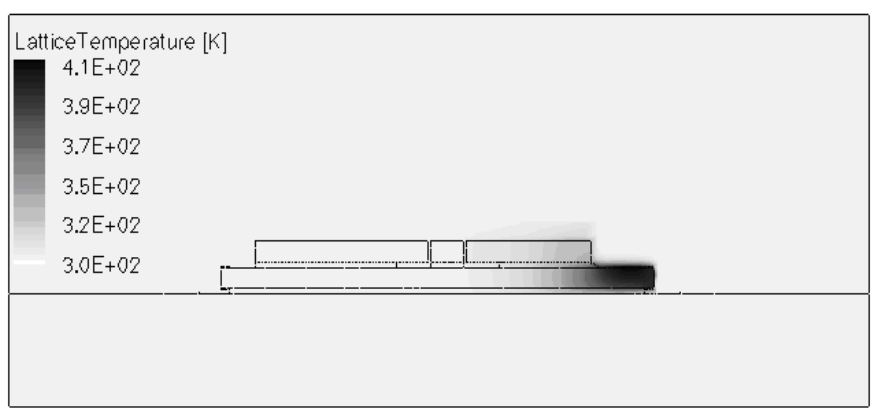

Fig. 3. Thermal profile showing a temperature gradient appearing on etch termination when the device is turned on.

\section{FEM DESCRIPTION}

An FEM has been created for the whole power device package. Boundary conditions are applied on each bottom corners of the resin, bottom-left corner is fixed and bottomright corner is blocked on $y$-axis (translation is allowed) (Fig. 2).

A 2-D cross section of the device is used to simplify the crack propagation modeling. The simulations have been performed using the ANSYS software (v14). Regarding the materials of the package and their behavior during the loading conditions (low variation of mechanical properties), the implanted linear elastic parameters are reported in Table I.

This model consists of 175000 quadratic plane-stress elements and 530000 nodes. For the crack tip modelling, which numerically corresponds to a singularity, degenerated triangular-shaped elements are required [17].

Two kinds of thermal conditions have been considered to study the different paths of crack propagation and determine the most critical cases. The first one is a uniform temperature applied on the whole structure. This thermal state corresponds to the operating steady state or to thermal 


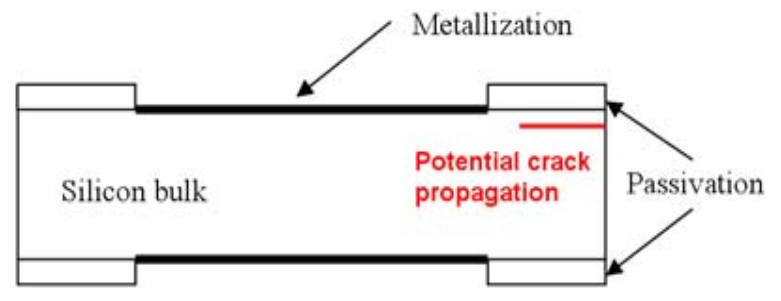

Fig. 4. Typical cross section of the power device studied. The potential crack propagation could occur through the silicon.

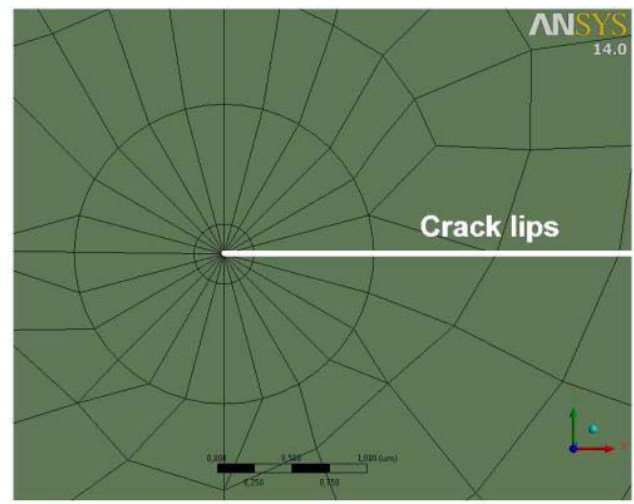

Fig. 5. Refined meshing around crack tip and crack lips.

stress sustained during thermal cycling test. The second one corresponds to the first electrical half-period after the device operation.

A hot spot is obtained in the silicon active region with a strong temperature level about $410 \mathrm{~K}$ (Fig. 3). Thermal distribution is calculated by electrothermal simulations for which thermal dependence of material properties has been considered, including Joule heating.

An initial crack is introduced in the silicon die (Fig. 4) by splitting the material. The crack propagation is modeled as a static growth; each simulation corresponds to a single crack length.

The $J$-integral method is known to be path-independent, but due to the crack length which is about two or three micrometers for the smallest, the contour integral do not always give stable results [18]. The meshing is refined to ensure this stability; especially, on the crack tip (Fig. 5), and get several contours for the $J$-integral. Thus, stress singularity on crack tip is apart and it can provide stable results.

Contact models are used to achieve the best match as possible regarding physical behavior of crack lips. Based on the normal Lagrange formulation, these models does not require any penetration to develop forces at the contact interface and prevent from any penetration unlike the traditional penalty formulations (Fig. 6).

1) All-bonded model between the whole structure and the resin (molding compound), materials are stuck together.

2) No separation model between etch termination near the crack and resin, frictions are allowed but resin cannot delaminate itself.

3) Frictionless model between crack lips to prevent overlap, separation is allowed.

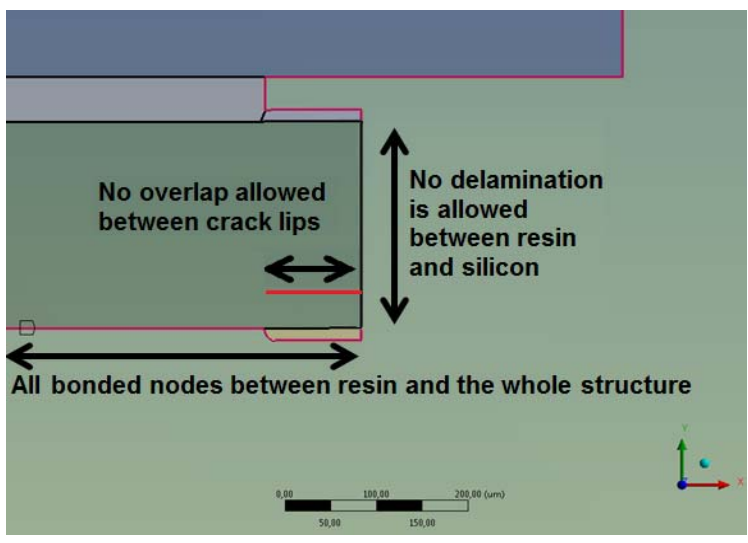

Fig. 6. Numerical contact models applied on the structure.

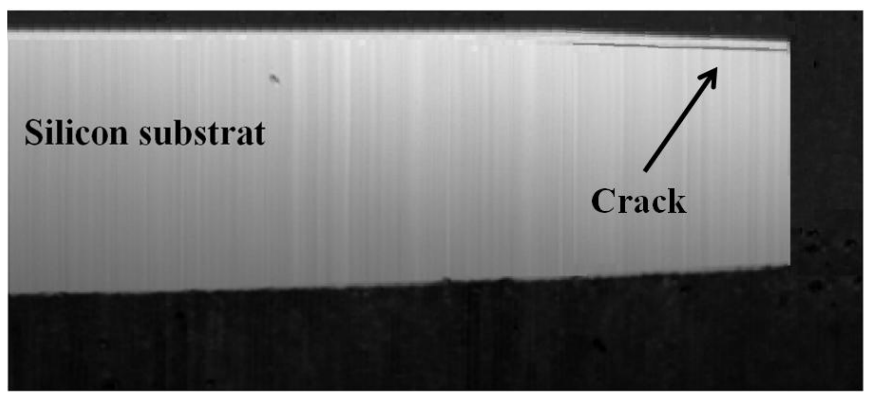

Fig. 7. Example of straight crack propagation in silicon and its position from passivation after thermal cycling test.

Residual stress in the resin has been also considered. Due to the molding process which is done at $175{ }^{\circ} \mathrm{C}$ during 2 min under pressure (100 bar), thermal strains are not relaxed at room temperature. Thus, the reference temperature of its coefficient of thermal expansion has been fixed to molding temperature $\left(T_{\text {ref }}=175^{\circ} \mathrm{C}\right)$.

\section{Straight Crack Propagation Analysis}

Accelerated life tests performed on critical samples (poor surface state at its baseline and many initial cracks) showed different crack propagation paths: straight, weak bifurcation and growth at the $\mathrm{Si} /$ passivation interface. The first case corresponds to a linear propagation through the silicon as indicated in Fig. 7.

\section{A. Influence of Temperature}

We have simulated each crack length and estimated the corresponding energy release rate value for different uniform temperature values $\left(50{ }^{\circ} \mathrm{C}-150{ }^{\circ} \mathrm{C}\right)$ applied on the whole structure as plotted in Fig. 8. The electrothermal profile has also been simulated.

Hence, a critical length value for all considered loads is highlighted. Propagation could occur when the corresponding energy release rate becomes higher than the critical energy release rate $\left(G_{\mathrm{c}}\right)$ of the silicon [4]. This one has been measured using the nano-indentation technique on several silicon wafers. Its value is close to $2 \mathrm{~J} / \mathrm{m}^{2}$ for $<111>$ crystal plane which is also assumed to be the most preferential plan for crack propagation [4]. 


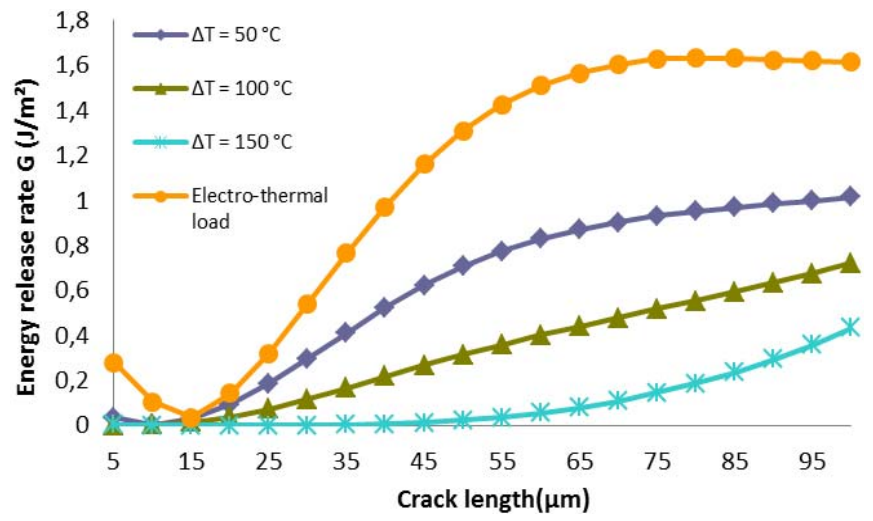

Fig. 8. Variation of energy release rate $G\left(\mathrm{~J} / \mathrm{m}^{2}\right)$ versus crack length $(\mu \mathrm{m})$ for different temperatures.

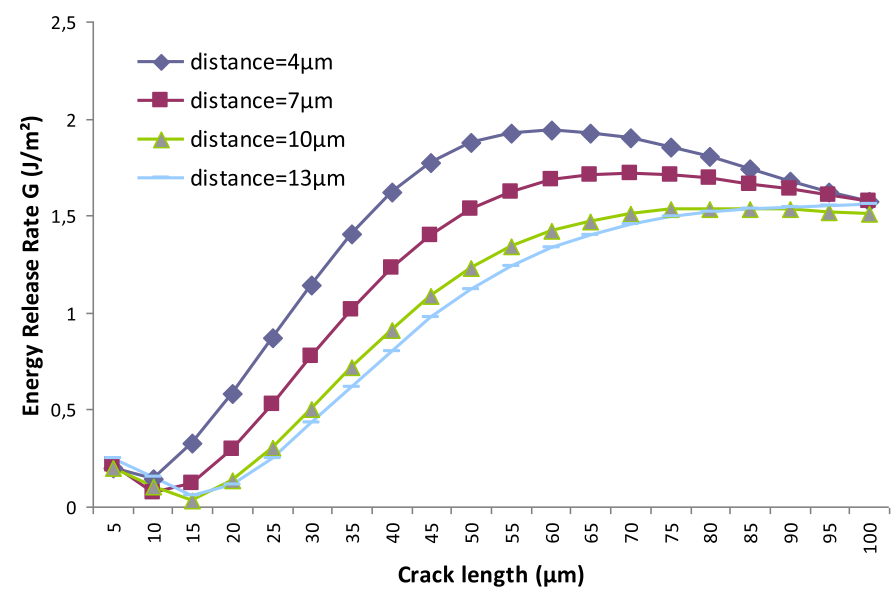

Fig. 9. Variation of energy release rate $G\left(\mathrm{~J} / \mathrm{m}^{2}\right)$ versus crack length $(\mu \mathrm{m})$ for different distance between crack and $\mathrm{Si} /$ passivation interface (electrothermal load).

We can also notice that a temperature variation leads to different critical crack lengths. The higher the temperature, the higher the critical crack length is. It can be explained by residual stress in the resin. Indeed, when the molding temperature is reached, most of the structure becomes stressfree and the silicon is less stressed. Moreover, no critical length can be found out for uniform thermal profiles, the energy release rates being much lower than the $G_{\mathrm{c}}$ parameter.

For electrothermal load, a single temperature spot on the silicon active region does not seem to be sufficient to enable crack growth but has more probability to initiate crack propagation than uniform thermal loads.

\section{B. Influence of the Distance from the Passivation}

The influence of both the distance from the nearest passivation interface and the initial crack length is now under investigations (Fig. 7). Electrothermal loading seem $\mathrm{s}$ to be the most critical load and is now used as reference. A large variation of energy release rate is noticed depending on this position, while $G$ is not affected by the distance for shorter crack lengths (up to $10 \mu \mathrm{m}$ ) (Fig. 9).

Above $10 \mu \mathrm{m}$ and up to $80 \mu \mathrm{m}$, it is clear that the distance from the passivation layer greatly impacts the crack

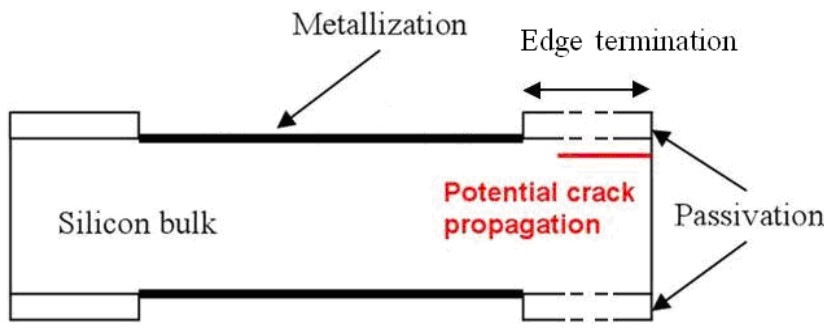

Fig. 10. Schematic variation of the edge termination length.

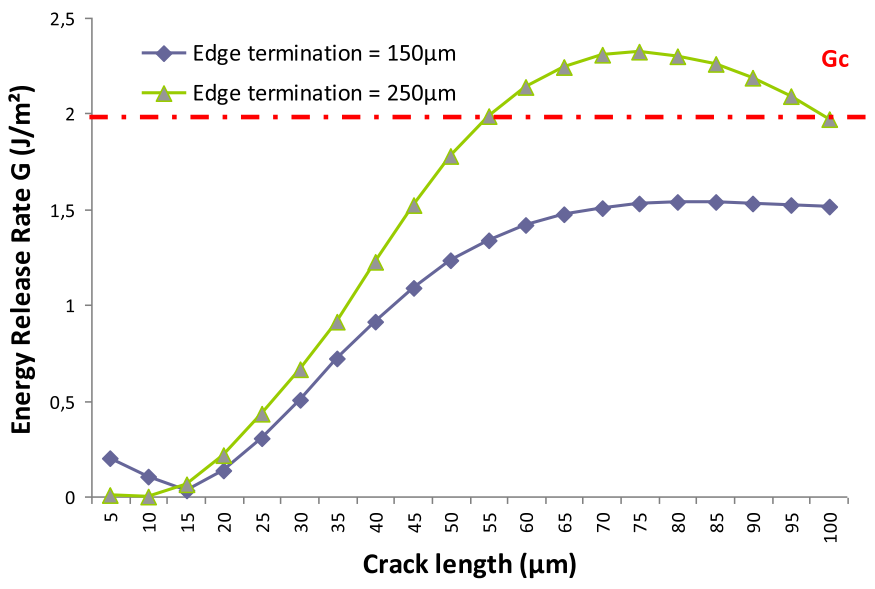

Fig. 11. Variation of energy release rate $G\left(\mathrm{~J} / \mathrm{m}^{2}\right)$ versus crack length $(\mu \mathrm{m})$ for two different junction edge termination sizes (electrothermal load, distance $=10 \mu \mathrm{m})$

propagation and corresponding energy release rate (i.e., $100 \%$ for both a distance between 4,13 and $50 \mu \mathrm{m}$ crack length).

Nevertheless, for such a temperature load no crack propagation threshold appears with variation of the initial crack profiles. Interfacial stress near the passivation seems to influence significantly the crack propagation: cracks close to the passivation have more risk to be propagated.

\section{Influence of Die Design}

According to the specifications of components (power supply, insulation, and function), various die and/or packages designs are used. The effect of these structures on crack propagation is evaluated. Two sizes of edge termination have been considered for simulations (Fig. 10): 150 and $250 \mu \mathrm{m}$.

The energy release rate is calculated in the two cases. The electrothermal profile is applied on the whole structure and different crack lengths ranging from 5 to $100 \mu \mathrm{m}$ are simulated (Fig. 11).

For shorter cracks until $15 \mu \mathrm{m}$, the short edge termination appears more sensitive to crack propagation. A large increase of the energy release rate is noticed for the longest junction edge termination. A crack would not be able to be propagated through the shortest width. For the longest edge termination width, a critical crack length appears at $56 \mu \mathrm{m}$, which corresponds to a very high crack length as compared to the average length of initial cracks. For both structures, an initial crack with a regular length about $10 \mu \mathrm{m}$ would never be propagated, but a large impact of dice designs on crack propagation can be noticed. 


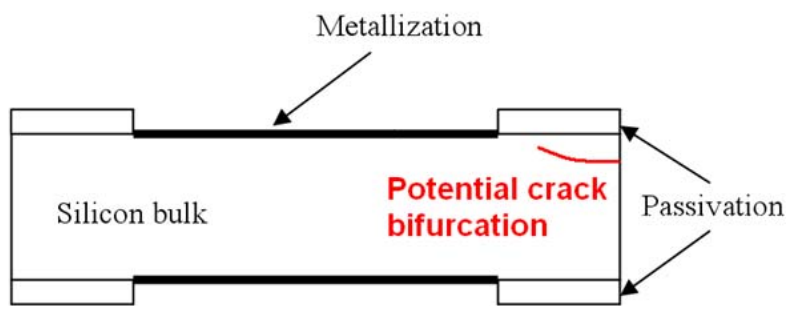

Fig. 12. Schematic crack propagation which bifurcated through silicon.

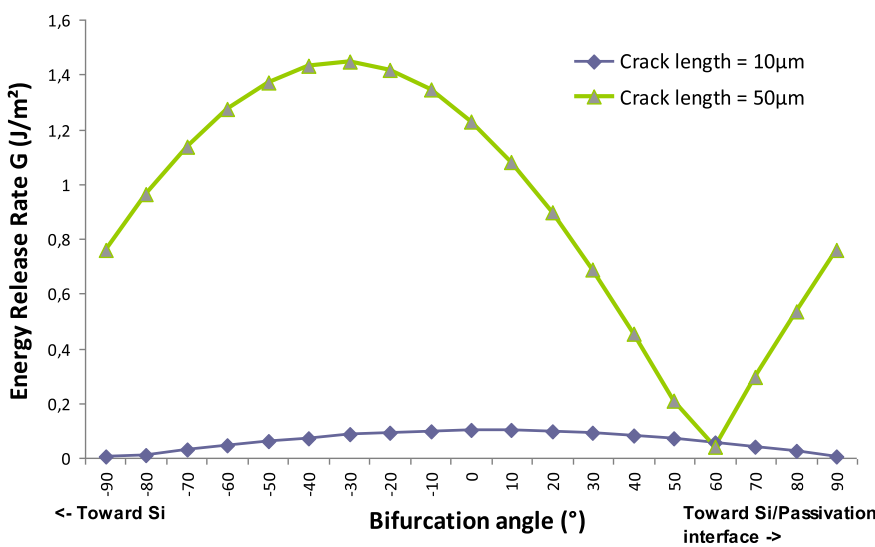

Fig. 13. Variation of energy release rate $G\left(\mathrm{~J} / \mathrm{m}^{2}\right)$ versus bifurcation angle $\left({ }^{\circ}\right)$ for two crack lengths of 10 and $50 \mu \mathrm{m}$ (electrothermal load, distance $=10 \mu \mathrm{m})$.

\section{Curved Crack Propagation Analysis}

The failure analysis also showed another crack path, which slowly bifurcate during the propagation (Fig. 12), and always toward the top Si/passivation interface. Hence, the possible crack bifurcation has been investigated.

Different approaches are available to evaluate crack bifurcation. Most of these models give equivalent results [19]. The maximum energy release rate criterion is chosen: crack will progress toward maximizing the energy release rate in front of the crack tip [20], [21].

To do determine the bifurcation direction, the $J$-integral method allows changing the normal plan of the crack and calculating the energy release rate for each virtual bifurcation angle [22].

Thus, it is possible to determine which angle is the most critical and what path crack will be followed. The $G$ parameter is calculated for each angle, from $-90^{\circ}$ (i.e., toward the inside of the silicon area) to $+90^{\circ}$ (i.e., toward the $\mathrm{Si} /$ passivation interface).

In a first time, bifurcation angle is determined for two specific crack lengths: a short one $(10 \mu \mathrm{m})$ as compared to a longer one equal to $50 \mu \mathrm{m}$ (Fig. 13).

For the shortest crack length, a straight propagation appears and the maximum value of the energy release rate corresponds to no bifurcation angle. If crack growth could occur for this length, it would not significantly bifurcate. Regarding the longest one, a weak bifurcation of about $30^{\circ}$ toward the Silicon is highlighted.

The impact of the distance between the crack and the $\mathrm{Si} /$ passivation interface on bifurcation angle is also studied. The results are reported in Fig. 14.

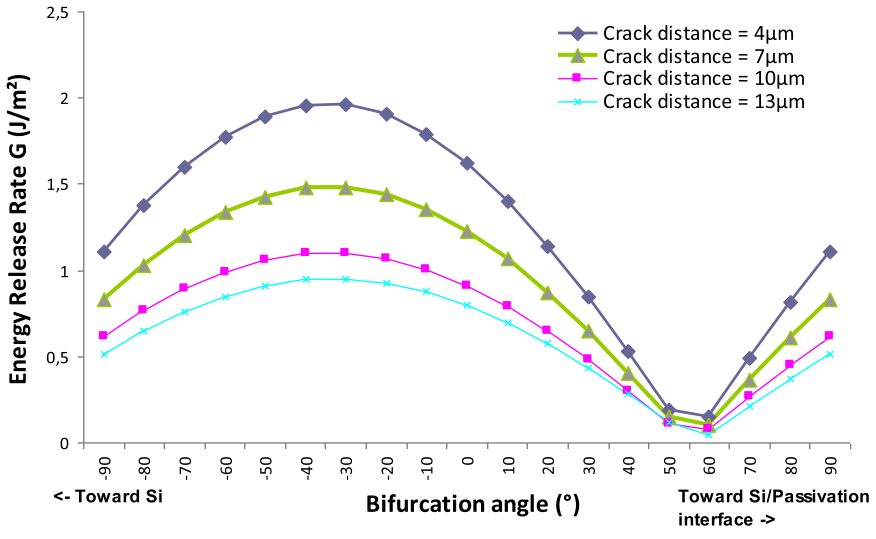

Fig. 14. Energy release rate $G\left(\mathrm{~J} / \mathrm{m}^{2}\right)$ versus bifurcation angle $\left(^{\circ}\right)$ for different distances between crack and $\mathrm{Si} /$ passivation interface (electrothermal load, crack length $=40 \mu \mathrm{m}$ ).

TABLE II

EFFECT OF COEFFicient OF THERMAL EXPANSION AND Young Modulus on ENERGy RelEase Rate For THREe Materials: Silicon, Resin ANd Passivation

\begin{tabular}{|c|c|c|c|c|c|c|}
\hline Effect on $\mathrm{G}$ & E_Resin & CTE_Resin & E_Passivation & CTE_Passivation & E_Si & CTE_Si \\
\hline $\begin{array}{c}\text { Crack_length }=5 \mu \mathrm{m} \\
\text { Distance }=4 \mu \mathrm{m} \\
\mathrm{G}=0.07 \mathrm{~J} / \mathrm{m}^{2}\end{array}$ & + & ++ & & + & + & - \\
\hline $\begin{array}{c}\text { Crack_length }=5 \mu \mathrm{m} \\
\text { Distance }=10 \mu \mathrm{m} \\
\mathrm{G}=0.03 \mathrm{~J} / \mathrm{m}^{2}\end{array}$ & & + & & + & + & \\
\hline $\begin{array}{c}\text { Crack_length }=45 \mu \mathrm{m} \\
\text { Distance }=4 \mu \mathrm{m} \\
\mathrm{G}=1.29 \mathrm{~J} / \mathrm{m}^{2}\end{array}$ & +++ & ++++ & - & & & - \\
\hline $\begin{array}{c}\text { Crack_length } \\
=45 \mu \mathrm{m} \\
\text { Distance }=10 \mu \mathrm{m} \\
\mathrm{G}=0.71 \mathrm{~J} / \mathrm{m}^{2}\end{array}$ & ++ & +++ & - & & & \\
\hline
\end{tabular}

A significant bifurcation angle about $30^{\circ}$ is found out toward the silicon regardless of the distance between the crack and the passivation interface. For an electrothermal load, the crack position has no effect on bifurcation angle.

\section{IMPACt OF MEChaniCAL PROPERTIES ON CRACK PROPAGATION}

To check the influence of the material properties on the energy release rate to get a better understanding on the most critical conditions for crack propagation ignition. A parametric variation has been done for several materials and their corresponding mechanical parameters: coefficient of thermal expansion (CTE) and Young's modulus $(E)$.

Most materials do not have any significant effect on the energy release rate and only those with a relevant effect were retained: resin, silicon, and passivation. The fracture criterion was calculated for four cases.

1) Shorter crack length $(5 \mu \mathrm{m})$ :

a) near the interface;

b) far from the interface.

2) Longer crack length $(45 \mu \mathrm{m})$ :

a) near the interface;

b) far from the interface. 


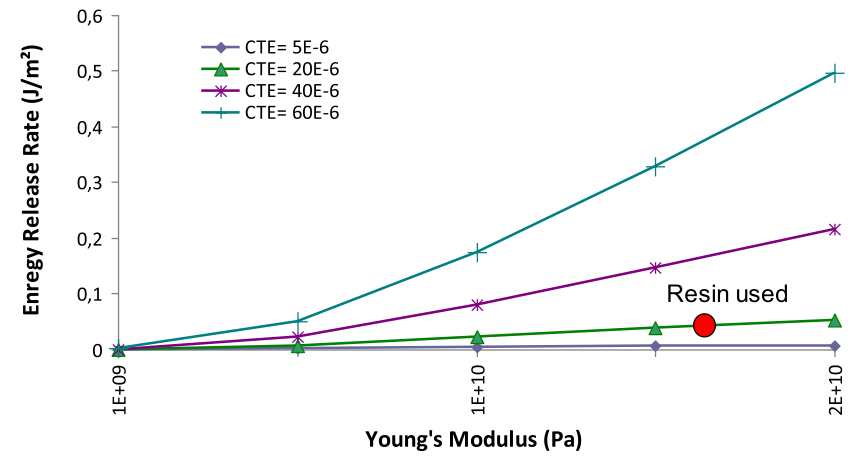

Fig. 15. Variation of nergy release rate $G\left(\mathrm{~J} / \mathrm{m}^{2}\right)$ versus Young's modulus (Pa) of resin considering different CTEs $\left(\mathrm{C}^{-1}\right)$ of resin (electrothermal load, crack length $=30 \mu \mathrm{m}$, distance $=10 \mu \mathrm{m})$.

Qualitative results are summarized in Table II taking into consideration that: + and - corresponds to the increase in the parameter in relation with an increase or a decrease of the energy release rate, respectively. The number of + or indicates the level of impact of the parameter.

One can observe an important effect of the resin on the energy release rate for both $E$ and CTE parameters. When the crack is longer, it appears a higher influence of these parameters on the energy release rate. Furthermore, when crack is near the passivation it can be also denoted an increase in the influence of these mechanical parameters. Silicon and passivation have also more impact on fracture criterion for shorter cracks, but barely as compared to the resin.

To confirm the important effect of the resin, energy release rate is estimated for a variation of the $E$ and CTE mechanical parameters related to the moulding compound (Fig. 15).

As expected, the results report a significant increase in the energy release rate especially when both Young's modulus and coefficient of thermal expansion get high. The current choice of parameters seems to be one of the best combinations to get the lowest energy release rate as possible.

\section{CONCLUSION}

This paper deals with a simplified and meaningful crack propagation model based on thermomechanical assumptions. It allows evaluating probability for this kind of failure on power devices under different thermal loadings. This model can help to determine which thermal conditions are the most critical for the silicon, and which one could lead to a failure.

The impact of temperature on critical crack length has been evaluated. No propagation thresholds appear for uniform thermal loads but electrothermal load seems to be the most critical thermal stress regarding crack growth. Crack bifurcation has also been investigated. The results indicate few influence of the distance from the crack with the passivation for electrothermal load. A bifurcation angle can be estimated depending on the crack position or length. A crack has more risk to bifurcate toward silicon when its length becomes longer.

Initial crack positions on silicon also affect significantly the corresponding energy release rates. A crack of $20 \mu \mathrm{m}$ will be four times more critical at $4 \mu \mathrm{m}$ instead of $13 \mu \mathrm{m}$ from the passivation interface. Furthermore, it has been shown that the resin is the material which has the highest impact on crack growth, especially when residual stresses are considered.

This model can also be used to predict which die designs are the most critical for crack propagation and to prevent early failures due to these crack propagation. It has been shown that a longer junction edge termination induces more probability to initiate a crack growth.

Moreover, failure analyses have also shown crack propagation at the $\mathrm{Si} /$ passivation interface due to a deflected crack growth or an initial defect located there. A material characterization of the separation surface energy between these two materials (silicon and passivation) will be carried out to investigate this propagation case. It will be performed using the microhardness indentation technique.

\section{REFERENCES}

[1] C. W. Zhao, Y. M. Xing, P. C. Bai, J. J. Li, Q. L. Liu, Y. G. Du, et al., "Crack tip dislocation emission and nanoscale deformation fields in silicon," Appl. Phys. A, Mater. Sci. Process., vol. 105, no. 1, pp. 207-210, Oct. 2011.

[2] T. Cramer, A. Wanner, and P. Gumbsch, "Energy dissipation and path instabilities in dynamic fracture of silicon single crystals," Phys. Rev. Lett., vol. 85, no. 4, pp. 788-791, 2000.

[3] A. M. Minor, E. T. Lilleodden, M. Jin, E. A. Stach, D. C. Chrzan, and J. W. Morris, "Room temperature dislocation plasticity in silicon," Phil. Mag., vol. 85, nos. 2-3, pp. 323-330, 2005.

[4] F. Ebrahimi and L. Kalwani, "Fracture anisotropy in single crystal silicon," Mater. Sci. Eng., A, vol. 268, nos. 1-2, pp. 116-126, Aug. 1999.

[5] P. Lall, S. Gupte, P. Choudhary, J. Suhling, and R. Darveaux, "Cohesivezone explicit sub-modeling for shock life-prediction in electronics," in Proc. 57th ECTC, Jun. 2007, pp. 515-527.

[6] H.-J. Schindler and C. Leinenbach, "Mechanics of fatigue crack growth in a bonding interface," Eng. Fract. Mech., vol. 89, pp. 52-64, Jul. 2012.

[7] M. Mayn, S. Kilchert, and S. Hiermaier, "3D model of fracture in brittle isotropic materials using a novel algorithm for the determination of the fracture plan orientation and crack surface area," Finite Elements Anal. Design, vol. 56, pp. 32-40, Sep. 2012.

[8] L. Mercado, "Evaluation of die edge cracking in flip-chip PBGA packages," IEEE Trans. Compon. Packag. Technol., vol. 26, no. 4, pp. 719-723, Dec. 2003.

[9] C. P. Chen and M. H. Leipold, "Fracture toughness of silicon," Amer. Ceram. Soc. Bull., vol. 59, no. 4, pp. 469-472, 1980.

[10] J. R. Rice, "A path independent integral and the approximate analysis of strain concentrations by notches and cracks," J. Appl. Mech., vol. 35, no. 2, pp. 379-386, Jun. 1968.

[11] E. F. Rybicki and M. F. Kanninen, "A Finite element calculation of stress intensity factors by a modified crack closure integral," Eng. Fract. Mech., vol. 9, no. 4, pp. 931-938, 1977.

[12] W. Thein, "Stress intensity factors determined by use of westergaard's stress functions," Eng. Fract. Mech., vol. 20, no. 1, pp. 65-73, 1984.

[13] C. P. Cherepanov, "Crack propagation in continous media," Appl. Math. Mech., vol. 31, no. 3, pp. 476-488, 1967.

[14] X. Li, T. Kasai, S. Nakao, T. Ando, M. Shikida, K. Sato, et al., "Anisotropy in fracture of single cristal silicon film characterized under uniaxial tensil condition," Sens. Actuators A, Phys., vol. 119, no. 1, pp. 143-150, Jan. 2005.

[15] N. O’Dowd, "Advanced fracture mechanics," Ph.D. dissertation, Dept. Mech. Eng., Imperial College London, London, U.K., 2003.

[16] S. Jacques, A. Caldeira, N. Batut, A. Schellmanns, R. Leroy, and L. Gonthier, "Lifetime prediction modeling of non-insulated TO-220AB packages with lead-based solder joints during power cycling," Microelectron. Rel., vol. 52, no. 1, pp. 212-216, Jan. 2012.

[17] ANSYS Help v13.0, Element Reference, ANSYS, Inc., Canonsburg, PA, USA, 2011.

[18] G. R. Irwin, "Fracture fynamics: Fracturing of metals," in Proc. ASM Symp. Fract. Met., Cleveland, OH, USA, 1948, pp. 147-166.

[19] J. B. Leblond, Mécanique de la Rupture Fragile et Ductile. Paris, France: Hermes Science, 2003. 
[20] F. Erdogan and G. C. Sih, "On the crack extension in plates under plane loading and traverse shear," ASME J. Basic Eng., vol. 85, no. 4, pp. 519-525, Dec. 1963.

[21] M.-S. Hou, X.-Q. Qian, and W. F. Bian, "Energy release rate and bifurcation angles of piezoelectric materials with antiplane moving crack," Int. J. Fract., vol. 107, no. 4, pp. 297-306, Feb. 2001.

[22] S. Liu, J. S. Zhu, J. M. Hu, and Y.-H. Pao, "Investigation of crack propagation in ceramic/conductive epoxy/glass systems," IEEE Trans. Compon., Packag., Manuf. Technol., Part A, vol. 26, no. 3, pp. 627-633, Sep. 1995.

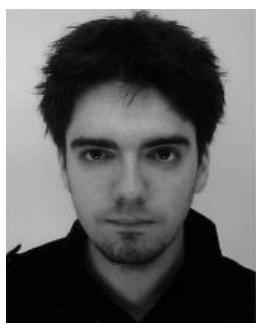

Damien Calvez received the master's degree in electronic reliability from the University Bordeaux 1 , Talence, France, in 2010, where he is currently pursuing the $\mathrm{Ph} . \mathrm{D}$. degree in microelectronic reliability in collaboration with STMicroelectronics. His thesis is focused on lifetime prediction of these components depending on geometric and technological variations.

$\mathrm{He}$ is currently with the IMS Laboratory of Talence, Talence, involved in reliability assessment of microelectronics power devices using finite element modeling and prediction models. He was involved in crack propagation modeling in silicon for power components.

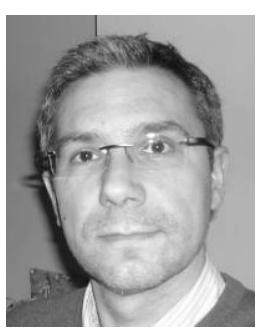

Fabrice Roqueta received the Ph.D. degree in electronics from the University of Tours, Tours, France, in 2000.

$\mathrm{He}$ is currently a TCAD Engineer with STMicroelectronics, Tours. His current research interests include finite element modeling concerning process and device simulation and thermal and mechanical simulation.

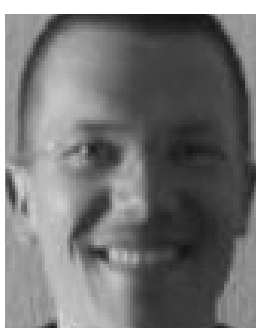

Sébastien Jacques received the Ph.D. degree in electronics from the University of Tours, Tours, France, in 2010. His research focused on the reliability study of semiconductor devices, assembled in through-hole packages, subjected to power cycling.

He was a Quality and Reliability Engineer with STMicroelectronics, Tours. He has been an Associate Professor since 2012. He joined GREMAN UMR-CNRS 7347 (research group specialized in microelectronics materials dedicated to electronics' applications, acoustics and nanotechnologies), University of Tours. His current research interests include energy conversion and energy efficiency, power devices and applications, and reliability.

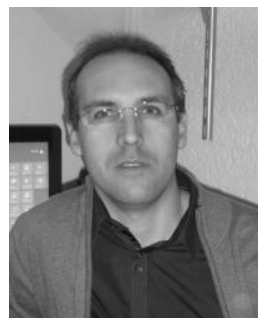

Laurent Bechou received the Ph.D. degree in electronics from the University Bordeaux 1, Talence, France, in 1998.

$\mathrm{He}$ joined the Integration of Material to System (IMS) Laboratory, University of Bordeaux 1, as an Associate Professor. He is currently a Full Professor of electronics and physics. He is currently the Manager of the Reliability Assessment of Micro and Nano-assemblied Devices Research Team (EDMiNA) with the IMS Laboratory. He is the co-author of more than 90 regular papers and international conferences. His current research interests include characterization, physical and failure mechanisms modeling and methods for reliability prediction of optoelectronic/photonic devices, light-emitting diodes, laser diodes, fiber laser, optical amplifier, photodetectors, fibered optical module for different applications in telecommunications, medical, and space.

Dr. Bechou received the Best Paper Award of the European Symposium on Reliability of Electron Devices, Failure Physics and Analysis in 2005 for a contribution on reliability assessment of InP-based semiconductor optical amplifier using physics of failure and original statistical methodology for lifetime distribution calculations in operating conditions. From 2004 to 2007, he was an active member of the COST 270 European Working Group on the Reliability of Optical Fiber Components, Devices, Systems, and Networks. Since 2009, he has been a member of the Steering Committee of the International Symposium on Reliability of Optoelectronics for Space.

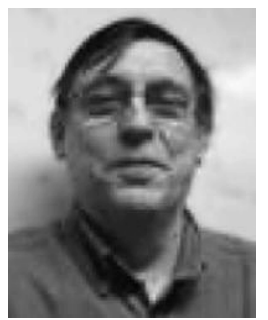

Yves Ousten (M'04) received the Ph.D. degree in sensors in thick film technology and their technological analysis from the University of Bordeaux 1, Talence, France, in 1989, and the Higher degrees in research in 1999 .

He has been a Professor of electronics and electrical engineering with the University of Bordeaux 1 since 2001. He is currently involved in linked to failure analysis and the development of nondestructive tools for the microassembly and packaging analysis. Those tools are based on the use of acoustics microscopy and the development of signal processing dedicated to the comprehension of images obtained with these techniques. He is involved in research for passive components electrical analysis. He is in charge of the team evaluation of the microassembly devices and is responsible for the European Reliability Network database for the reliability simulation and prediction.

Dr. Ousten was an Elected Official of the International Microelectronics and Packaging Society France Director Committee, and is a member of the IEEE Components, Packaging, and Manufacturing Technology Society.

Samuel Ducret, photograph and biography are not available at the time of publication. 